\title{
O paradoxo da natureza humana: fundamentos dos Direitos Humanos a partir dos direitos LGBTI+ ${ }^{1}$
}

\author{
The paradox of human nature: fundamentals of Human Rights based on LGBTI+ rights \\ La paradoja de la naturaleza humana: fundamentos de los Derechos Humanos basados en los \\ derechos de LGBTI+
}

Recebido: 10/11/2021 | Revisado: 17/11/2021 | Aceito: 22/11/2021 | Publicado: 05/12/2021

\author{
Andressa Regina Bissolotti dos Santos \\ ORCID: https://orcid.org/0000-0002-5371-8994 \\ Universidade Federal do Paraná, Brasil \\ Faculdade de Pinhais, Brasil \\ E-mail: bissolottiandressa@gmail.com
}

\begin{abstract}
Resumo
Nas clássicas teorias acerca dos Direitos Humanos, esses são pensados como decorrentes de uma certa "natureza humana", no sentido de que tais direitos se depreenderiam imediatamente de uma dignidade fundante da categoria do "humano". Tal afirmação simplória, no entanto, se coloca em paradoxo com a imensa dificuldade de garantia de direitos humanos à coletividades inteiras, especialmente quando estão em operação formas excludentes de compreensão do humano, ligadas a nacionalismos, racializações, ou a experiências de gênero e sexualidade compreendidas como "desviantes". Nessas últimas, o paradoxo da natureza humana mostra-se em sua crueza, tendo em vista que as vivências de grupos LGBTI+ foram historicamente identificadas como "não naturais". As demandas por direitos de pessoas LGBTI+, assim, vêm acompanhadas no contexto mundial de uma demanda por integrar a categoria do humano, inclusive apelando-se, em alguns casos, para compreensões bio-ontológicas da definição da sexualidade humana como argumento chave. Tal postura possui o evidente objetivo de naturalizar a experiência LGBTI+, disputando assim quais experiências corpóreas e sexuais a categoria do humano pode "naturalmente" conter. Com o objetivo de explorar e questionar a realidade narrada e através de uma metodologia de fundo ensaísta, este artigo demonstra que tal movimento mostra um paradoxo: ao passo que o fundamento na natureza humana é com frequência colocado como uma forma de proteger os direitos de tendências excludentes e reducionistas, ele é em si mesmo excludente, no sentido de que a "natureza humana" não possui um sentido ontológico único a ser descoberto, mas é ela mesma socialmente definida. Ao desenvolver essa problemática, este trabalho procura dialogar com perspectivas da filosofia contemporânea e especialmente com a obra de Judith Butler, a qual nos mostra que toda ontologia, em especial aquela relacionada às identidades sexuais e de gênero, é histórica. Assim é também a "natureza humana", sendo necessário questionar os sentidos que esta ocupa como fundamento dos direitos humanos. À guisa de conclusão, propõe-se pensar os direitos humanos a partir de fundamentos contingentes, no sentido trazido por Butler, que para cumprirem seu papel de expansão de formas vivíveis de vida, devem permanecer sempre abertos à contestação e à ampliação de suas fronteiras, incluindo novas experiências humanas.
\end{abstract}

Palavras-chave: Teoria dos Direitos Humanos; Direitos LGBTI+; Natureza humana.

\begin{abstract}
In the classic theories about Human Rights, these are thought to stem from a certain "human nature", in the sense that such rights would immediately be derived from a founding dignity of the "human" category. Such a simple statement, however, is paradoxical with the immense difficulty in guaranteeing human rights to entire communities, especially when exclusionary ways of understanding the human are in operation, linked to nationalisms, racializations, or to experiences of gender and sexuality understood as "deviants". In the latter, the paradox of human nature is shown in its crudity, given that the experiences of LGBTI + groups have historically been identified as "unnatural". The demands for rights of LGBTI + people, therefore, have been accompanied in the world context by a demand to integrate the category of the human, including appealing, in some cases, to bio-ontological understandings of the definition of human sexuality as a key argument. Such a posture has the evident objective of naturalizing the LGBTI + experience, thus disputing which bodily and sexual experiences the category of the human can "naturally" contain. With the aim of exploring and questioning the narrated reality and through an essayist-based methodology, this article demonstrates that such a movement shows a paradox: while the foundation in human nature is often placed as a way to protect the rights
\end{abstract}

\footnotetext{
${ }^{1}$ O presente trabalho foi realizado com apoio da Coordenação de Aperfeiçoamento de Pessoal de Nível Superior - Brasil (CAPES) - Código de Financiamento 001.
} 
of exclusionary and reductionist tendencies, it is in itself exclusionary, in the sense that "human nature" does not have a unique ontological meaning to be discovered, but is itself socially defined. In developing this problem, this work seeks to dialogue with perspectives of contemporary philosophy, and specially with Judith Butler's work, which show us that all ontology, especially that related to sexual and gender identities, is historical. So is "human nature", and it is necessary to question the meanings it occupies as the foundation of human rights. In a provisory conclusion, it is proposed to think about human rights from contingent foundations, in the sense brought by Butler, which, in order to fulfill their role of expanding livable forms of life, must always remain open to contestation and to the expansion of their borders, including new human experiences.

Keywords: Human Rights Theory; LGBTI + rights; Human nature.

\section{Resumen}

En las teorías clásicas sobre los derechos humanos, se piensa que estos se derivan de una cierta "naturaleza humana", en el sentido de que tales derechos se derivarían inmediatamente de una dignidad fundacional de la categoría "humana". Una afirmación tan simple, sin embargo, resulta paradójica con la inmensa dificultad de garantizar los derechos humanos a comunidades enteras, especialmente cuando operan formas excluyentes de entender lo humano, vinculadas a nacionalismos, racializaciones, o a experiencias de género y sexualidad entendidas como "desviadas". En este último, la paradoja de la naturaleza humana se muestra en su crudeza, dado que las experiencias de los grupos LGBTI + han sido históricamente identificadas como "antinaturales". Así, las demandas por los derechos de las personas LGBTI + han ido acompañadas en el contexto mundial de una demanda de integración de la categoría de lo humano, apelando, en algunos casos, a las comprensiones bio-ontológicas de la definición de sexualidad humana como argumento clave. Tal postura tiene el objetivo evidente de naturalizar la experiencia LGBTI +, disputando así qué experiencias corporales y sexuales puede contener "naturalmente" la categoría de lo humano. Con el objetivo de explorar y cuestionar la realidad narrada y a través de una metodología de base ensayista, este artículo demuestra que tal movimiento muestra una paradoja: si bien el fundamento en la naturaleza humana a menudo se coloca como una forma de proteger los derechos de las tendencias excluyentes y reduccionistas, es en sí mismo excluyente, en el sentido de que la "naturaleza humana" no tiene un significado ontológico único por descubrir, sino que ella misma está socialmente definida. Al desarrollar este problema, este trabajo busca dialogar con perspectivas de la filosofía contemporánea, especialmente el trabajo de Judith Butler, que nos muestra que toda ontología, especialmente la relacionada con las identidades sexuales y de género, es histórica. También lo es la "naturaleza humana", y es necesario cuestionar los significados que ocupa como fundamento de los derechos humanos. A modo de conclusión, se propone pensar en los derechos humanos desde bases contingentes, en el sentido planteado por Butler, qué, para cumplir su rol de expandir formas de vida habitables, debe permanecer siempre abierto a la impugnación y a la expansión de sus fronteras, incluidas nuevas experiencias humanas.

Palabras clave: Teoría de los derechos humanos; Derechos LGBTI+; La naturaleza humana.

\section{Introdução}

Esse trabalho visa compreender a mobilização da categoria de 'natureza humana' nos processos de luta por direitos da população LGBTI+ no Brasil e, a partir dessa concretude, refletir sobre a permanência da natureza humana (especialmente a partir da sua tradução no conceito de 'dignidade humana') como fundamento dos direitos humanos, bem como os paradoxos que isso coloca.

Retoma-se assim o desafio de pensar o que há por trás dessa categoria, tão central nas discussões jurídicas e políticas do presente e já tão questionada tendo em vista suas definições historicamente excludentes. A análise propõe que investigar o que está em jogo nos debates acerca dos direitos humanos LGBTI+ permite questionar de forma mais geral o que está envolvido na criação e no funcionamento dos direitos e dos direitos humanos, de maneira mais geral.

Acima de tudo, se inicia a partir da compreensão do problema decorrente do fato de que a anunciação geral de que todos os humanos possuem direitos, não se faz seguir de uma distribuição efetiva do acesso a esses direitos. Parte determinante da resposta parece ser que o conceito de humano que subjaz à noção de direitos tais como 'direitos humanos', fundamentando-os, longe de ser ampla o suficiente a ponto de incluir a diversidade humana, está baseada em 'gramáticas de dignidade humana' bastante excludentes (Santos \& Martins, 2019).

Assim, o paradoxo existente na disputa por direitos humanos LGBTI+ escancara o fato de que a questão da contemporaneidade parece não ser apenas quais são os direitos humanos disponíveis, mas a quem são eles aplicáveis. Afinal, pessoas LGBTI+ (assim como outros grupos excluídos da estrita gramática da dignidade humana que fundamenta esses direitos) não têm demandado novos direitos, apenas a aplicação a si de direitos já consagrados. Apesar disso, os processos de luta por 
direitos permanecem custosos e avançam a passos lentos, o que gera o questionamento do que subjaz à essa problemática.

\section{Metodologia}

A partir da identificação da exclusão de certas coletividades de pessoas do acesso aos direitos humanos, aplica-se uma metodologia ensaística que oferece um enquadramento teórico possível para a problemática selecionada. O ensaio possibilita a inclusão da prática crítica na própria forma do fazer ciência. Tendo em vista o objetivo de questionar os elementos constitutivos da exclusão cultural da população LGBTI+ do acesso aos direitos humanos, o ensaio surge como a abordagem mais adequada, incorporando na própria forma o conteúdo buscado, por reconhecer a historicidade e localização do próprio fazer científico ao "buscar o teor de verdade como algo histórico por si mesmo" (Adorno, 2003, p. 27).

Assim, parte-se de pesquisa bibliográfica, com análise da literatura do campo dos direitos humanos e do campo do gênero e da sexualidade e a partir dela o ensaio é construído, em uma trama que relaciona os problemas colocados sob a lupa da análise e dos conceitos oferecidos. A identificação de que noções concernentes à natureza humana subjazem nos discursos contrários e favoráveis aos direitos humanos LGBTI+, por outro lado, surge como resultado parcial de pesquisa empírica em desenvolvimento no doutoramento da pesquisadora, a partir da análise das manifestações da sociedade civil organizada através do instrumento do amicus curiae na ADI 4277/ADPF 132 e na ADI 5668, todas tendo tramitado ou tramitando na Corte Constitucional brasileira. Ressalte-se, no entanto, que o presente artigo não traz os resultados da dita pesquisa diretamente, vez que estão ainda em curso, mas que a identificação do manejo comum de noções de natureza como fundamento dos direitos humanos já é um resultado parcial da pesquisa. Esse resultado é então colocado como problema pelo presente artigo, e através do fazer ensaísta é confrontado com reflexão conceitual sustentada por pesquisa bibliográfica.

\section{Resultados e Discussão}

Que uma população como a LGBTI+ precise lutar para acessar direitos humanos, os quais se afirmam desde o pósguerra como inerentes a todos os seres humanos, isso evidencia a forma paradoxal através das quais esses direitos são na verdade diferencialmente aplicados a depender dos sujeitos em vista e de sua localização mais ou menos distante em relação aos parâmetros socialmente difundidos do que seja o 'humano' e sua 'natureza'.

Isso demonstra, enfim, que toda 'declaração' de direitos na verdade inventa ou constitui aqueles direitos que são afirmados como autoevidentes (Hunt, 2012), e o faz tendo em vista sujeitos específicos aos quais serão aplicados, a partir dos enquadramentos através dos quais o ‘humano’ é reconhecido no momento da declaração (Butler, 2015).

Assim, as históricas reivindicações de direitos têm convivido com inclusões apenas parciais, além de exclusões em alguns casos claras. Tenha-se como exemplo a clássica "Declaração dos Direitos do Homem e do Cidadão", a qual não estendia quaisquer dos direitos ali previstos às mulheres. Tenha-se em mente, aliás, que a situação geral das mulheres não apenas não melhorou durante o período revolucionário na França, como deteriorou (Kingdom, 1991).

Também no contexto da fundação da nação 'democrática' do Norte Global tal paradoxo se coloca. No norteamericano Naturalization Act de 1790, o status de cidadão é conferido apenas à homens brancos, livres e de 'bom caráter' (Costa, 2015).

Esses exemplos históricos demonstram que a construção da ideia de direitos inerentes aos seres humanos tem convivido com concepções excludentes de quem são esses humanos. Nesse sentido, é interessante considerar como o fundamento daquilo que podemos chamar direitos humanos convencionais ou hegemônicos (Santos \& Martins, 2019), permanece sendo até hoje uma gramática de dignidade humana que decorre da filosofia kantiana. Esses direitos estão ainda firmados, portanto, em uma concepção ocidental (e colonial) acerca do humano (Maldonado-Torres, 2019), repercutindo em exclusões globais baseadas em gênero, raça, classe, sexualidade, entre outros marcadores.

Assim, por sua historicidade, os direitos humanos possuem certo enraizamento em um conceito de dignidade definido 
como decorrente da própria natureza humana e que tem gerado exclusões insistentes. As disputas de diferentes grupos por direitos humanos, enfim, parecem com frequência ser disputas pelo direito de ocupar o conceito de humano e de questionar quais são os atributos que naturalmente o definem, muito mais do que o arrolamento do que seriam 'novos' direitos. Ou seja: os direitos em si, com frequência, são aqueles já vivenciados pelos grupos de pessoas que cumprem os critérios colocados pelos enquadramentos de humano em jogo (Butler, 2015), de forma que 'novos' são na verdade os sujeitos a reivindicá-los.

Esse sujeito, a quem foi originalmente atribuído direitos em decorrência da dignidade que possui por natureza, é historicamente um sujeito masculino, já que o indivíduo moderno é marcadamente masculino (Felski, 1995), mas também heterossexual e cisgênero. Isso porque, como nos sugere Butler (2007), as normas culturais determinam uma pretensamente 'natural' coerência entre corpo - gênero - desejo, inscrevendo assim a heterossexualidade cisgênera como única expressão normal (ou, enfim, natural) da sexualidade humana. A partir disso, as experiências e vivências de pessoas LGBTI+ foram historicamente identificadas como 'não naturais' e esquadrinhadas pelos saberes científicos (Foucault, 2014). Se os direitos decorrem daquilo concernente à natureza do humano (de onde advém sua dignidade), dessas experiências categorizadas como desviantes em relação a essa natureza acabaria por não decorrer direitos, a não ser que se questione o próprio conceito de humano 'natural' que a eles subjaz.

Tendo em vista que essas vivências diversas foram historicamente identificadas como 'não naturais', é possível então observar que as demandas por direitos de pessoas LGBTI+ vêm acompanhadas de uma demanda por integrar a categoria do humano, inclusive apelando-se, em alguns casos, para compreensões bio-ontológicas da definição da sexualidade humana como argumento chave (Jackson, 1998). Tal postura possui o evidente objetivo de naturalizar a experiência LGBTI+, disputando assim quais experiências corpóreas e sexuais a categoria do humano pode 'naturalmente' conter.

Ou seja: vê-se nessas estratégias não a necessidade de construção de direitos novos. Mas a necessidade de construção de novas percepções culturais sobre o que seja o humano e a sua natureza, para então acessar aqueles direitos já garantidos a outras categorias de pessoas.

Já os discursos de resistência ao avanço dos direitos de pessoas LGBTI+ vão insistir na heterossexualidade como única expressão natural da sexualidade humana, visualizando a família heterossexual como um elemento natural fundamental para a organização humana, sem o qual a sociedade não existiria como tal (Haider-Markel, 2001). Na visão de quem resiste a esses direitos, aceitar formas outras de sexualidade e de 'família' equivaleria a deturpar e destruir aquilo que se compreende como inscrito, num sentido mesmo biológico, no âmbito da natureza.

Vejamos, por exemplo, as disputas e pânicos gerados na discussão do pacto civil na França (Butler, 2003), ou os mais recentes discursos catastróficos sobre a destruição da sociedade caso a chamada 'ideologia de gênero' viesse a ser permitida nas escolas brasileiras (Miskolci \& Campana, 2017).

Um lado, enfim, demanda a compreensão das experiências LGBTI+ como naturalmente humanas, de forma que essas pessoas seriam então detentoras dos direitos garantidos a todos os 'humanos'. O outro, por seu turno, procura localizar essas experiências como deturpações da natureza humana, localizando então essas pessoas não como humanas a serem protegidas pelos direitos, mas como verdadeiras ameaças às coletividades que de fato deveriam ser protegidas (Foucault, 2010), justificando assim a exclusão desse grupo do acesso aos direitos garantidos a todos os 'humanos'.

Vê-se, enfim, o paradoxo. É que as estratégias partem de um ponto em comum, embora tenham objetivos políticos e consequências culturais profundamente diversas. O ponto comum é que o fundamento dos direitos humanos permanece sendo vinculado a uma certa compreensão da natureza humana, teoricamente pré-discursiva e compartilhada por todos os indivíduos que contam para os direitos, o que justificaria um tratamento igual e adequado à dignidade humana que todos eles possuem. $\mathrm{O}$ que as faz diferir é a identificação de quais são os atributos que compõem essa natureza.

Os termos em que esses debates se dão na atualidade demonstram, enfim, o quanto o conceito de natureza humana 
permanece pautando as disputas sobre direitos humanos, apesar da já existência de teorias críticas que questionam sua utilidade como fundamento desses direitos. É dizer, as discussões amplas sobre direitos humanos permanecem pautadas em uma compreensão 'tradicional' desses direitos, a qual se mantém devedora do humanismo racional moderno, pressupondo a existência de direitos inerentes a uma certa natureza humana, calcada em concepções ahistóricas e metafísicas acerca da existência e do destinatário dos direitos.

De fato, preceitos profundamente kantianos como o homem tomado sempre como um fim em si mesmo, influenciam profundamente o pensamento dos juristas em termos de direitos humanos, consciente ou mesmo inconscientemente. A construção desse preceito em abstrato, no entanto, não pode escapar do fato de que na hermenêutica realizada quando da aplicação das normas, são as percepções culturais vigentes que definirão afinal qual é o sentido das palavras (Ruzyk, 2019), de forma que qualquer aplicação de Direitos Humanos será sempre contextual e localizada.

A influência dessas visões de direitos humanos é tão intensa, que mesmo as teorias críticas dos direitos humanos, as quais criticaram as compreensões tradicionais dos direitos humanos, permanecem em flerte com elas. Vejamos a teoria de Flores (2009). O autor apresenta uma concepção de direitos humanos diversa da tradicional, a qual leva ao entendimento dos direitos humanos não apenas como aqueles enunciados em tratados e convenções internacionais e também não como categorias prévias à ação política, mas sim como resultado das lutas das pessoas concretas por uma vida digna. Apesar dos relevantes deslocamentos, o conceito de 'dignidade humana' permanece como categoria capaz de identificar os direitos humanos: os direitos humanos são aqueles formados a partir de lutas que tem como objetivo a realização da dignidade humana.

Mas o que seria essa dignidade humana? Nesse ponto, é interessante compreender como mesmo diante de disputas de direitos que questionem as concepções dominantes acerca do humano, exigindo a inclusão de novas formas de ser nessa categoria, a manutenção dela como fundamento último dos direitos parece (re)inscrever os direitos humanos em um ciclo constante de exclusões.

Vejamos, nesse sentido, como nos próprios processos de luta por direitos do movimento LGBTI+, a literatura vem demonstrando que as disputas pela inclusão dessa população no conceito de humano que subjaz aos direitos levam muitas vezes a inclusões apenas parciais. É que para se afirmar como humano a estratégia utilizada é muitas vezes aquela de reforçar os atributos em comum com a norma padrão, gerando a desvalorização daquilo que pode ser identificado como 'marginal' nessas experiências (Miskolci, 2007). Ou seja, essa inclusão acaba por gerar exclusões dentro do próprio grupo que se procura incluir, naquilo que Butler (2007) chamou 'deslegitimação seletiva'. Assim, vemos como os discursos em defesa dos direitos de pessoas LGBTI+ com frequência marcam como representativa do grupo uma homossexualidade "conjugal, monogâmica, branqueada, classe média urbana, psicologizada" (Paiva, 2007, p. 24). Vemos, enfim, a construção daquilo que a literatura chamou "minoria modelo' (Bernstein \& Reimann, 2001). Parte das consequências desse fato pode ser visualizada na forma como a violência se distribui de formas desiguais dentro da própria comunidade LGBTI+ brasileira (Formento \& Almeida, 2020).

É necessário então problematizar a manutenção da existência de noções metafísicas (tais como uma dignidade humana calcada na natureza) na identificação dos destinatários dos direitos. Seja nas gramáticas tradicionais ou críticas dos direitos humanos, tal manutenção acaba por funcionar como um agente discursivo limitador - ou seja, como um conceito que parece acabar sempre por transformar as disputas por direitos humanos em discussões metafísicas sobre a natureza humana, com consequências muitas vezes indesejáveis.

Para pensar nos termos de um filósofo profundamente moderno e extremamente influenciador do pensamento jurídico, podemos passar ligeiramente sobre a emergência de uma concepção de dignidade a partir do pensamento kantiano. O indivíduo kantiano é concebido como racional, independente e livre, no sentido em que a liberdade é mover-se conforme as leis colocadas para si mesmo (Morrison, 2006). Esse indivíduo, assim, guarda grande semelhança com as conceções ideais e normativas que subjazem à categoria do homem moderno e, assim, também ao sujeito de direito. Quando o padrão de sujeito é evocado na Lei 
ou na doutrina ele frequentemente estabelece uma conexão com esse indivíduo kantiano, movido por uma racionalidade que lhe confere autonomia e liberdade, fortemente marcado por um ideário de capacidade que somente é conferida por essa maioridade racional.

A dignidade, nesse contexto, advém da capacidade humana de usar a razão (Morrison, 2006). A dignidade do indivíduo está no fato de que este não obedece senão as leis postas por ele mesmo - objetivamente definidas através dos a priori da razão - e no fato de que o homem é fim em si mesmo, jamais podendo ser usado como meio para alguma coisa (Andrade, 2000).

$\mathrm{Na}$ teoria tradicional dos direitos humanos é fácil identificar as semelhanças com esse pensamento. A defesa de direitos inatos ao homem, universalizáveis, transcendentais - porque independentes de cultura ou contexto histórico -, os quais versam sobre a proteção do homem como fim último do direito e da sociedade, mostra a insistência de uma certa raiz kantiana nessa abordagem.

Mas também na chamada Teoria Crítica dos Direitos Humanos é possível ver certas permanências desse pensamento. A insistência em reivindicar o uso do termo dignidade parece, igualmente, manter uma opção de ver a finalidade das lutas nesse sentido kantiano do homem em sua dignidade porque fim em si mesmo, como ser racional e capaz de estabelecer as próprias leis. Maior mobilidade e historicidade, portanto, mas talvez não menor dívida com o conceito moderno e humanista da dignidade do indivíduo kantiano.

Os riscos de mobilizar essa categoria humanista de indivíduo - ou de sujeito -, tantas e tantos autores têm nos mostrado na contemporaneidade. Felski (1995), por um lado, sinaliza que os atributos do indivíduo moderno, em sua independência, racionalidade e autonomia, são atributos masculinos, não generalizáveis às mulheres dentro da cultura Ocidental. O próprio Foucault (2008), ao pensar a norma como uma espécie de parâmetro, de modelo, para as práticas e discursos de subjetivação e sujeição, pode ser aqui mobilizado para pensarmos o quanto esse conceito de dignidade humana comunica um modelo específico de sujeito, de natureza humana, de luta por direitos, quando soa aos ouvidos ocidentais.

A reflexão de Butler (2007) acerca dos limites do uso do conceito de mulher como sujeito político do feminismo também deve ser lembrada. Assim como acontece com o conceito de mulher, reivindicar o conceito de dignidade não é simplesmente lançar mão de realidades pré-existentes, mas produz a noção mesma de dignidade, marcando fronteiras constitutivas e abjetas daquilo que não é digno ou suficientemente humano. A dignidade, nesse sentido, poderia ser significada como um dentre tantos enquadramentos (Butler, 2015) a atuar quando o conceito de direitos humanos é mobilizado. É nesses termos em que, portanto, continuar utilizando a dignidade após pretender desenredar as lutas por direitos de sua percepção ocidental humanista, parece ser uma opção um tanto contraditória, mas principalmente contraproducente.

Além disso, a opção pelo termo dignidade, a permanência dessa conexão com a noção kantiana do que é o Homem e a Humanidade, pode ser criticamente apontada como um sinal de que a terceira via ofertada pela Teoria Crítica dos Direitos Humanos acaba por aproximar-se em pontos centrais da teoria tradicional, em detrimento daquilo que o multiculturalismo teria de talvez mais rico a oferecer: a desestabilização de quaisquer fundamentos naturalistas dos direitos - o que, aliás, é afirmado por Flores como sendo sua intenção.

Assim, para grupos como as pessoas LGBTI+, bem como diversos outros grupos de pessoas que por diferentes marcadores não se enquadram nas concepções tradicionais de humano, parece ser relevante questionar as estratégias de lutas baseadas em concepções naturalistas da humanidade e do humano. É de se questionar, enfim, se não haveria forma outra de fundamentar os direitos humanos, de forma a se abrir mão de qualquer concepção naturalística, ahistórica e metafísica destes.

Questiona-se, então, até que ponto a insistência no conceito de 'dignidade humana' não permanece nos empurrando novamente ao humanismo excludente da modernidade; não permanece, sempre, nos forçando a buscar aproximações com a categoria normativa de humano, para que possamos então ganhar o direito a possuir esses direitos humanos.

A maior disputa hoje em termos de direitos humanos, portanto, parece permanecer sendo não quais são os direitos que 
possuem as pessoas humanas, mas quem são esses humanos que possuem direitos. Assim, para aqueles que se afastam dos enquadramentos hegemônicos que definem o "humano" e/ou o "natural", colocam-se obstáculos a todo momento, seja no âmbito da sua própria inclusão na sociedade a partir do universo do trabalho (Ribeiro et al., 2020), seja em sua exposição extrema à violência e à morte (Formento \& Almeida, 2020).

A partir dessas problematizações, propõe-se que uma compreensão contemporânea de 'direitos humanos' requeira o abandono da noção de 'dignidade humana', na medida em que esta permanece vinculada à ideia de natureza humana. Isso porque uma teoria verdadeiramente ampla de 'direitos humanos' requer o abandono de qualquer sentido metafísico de 'natureza humana', propondo-se que qualquer sentido de natureza humana é histórico e, portanto, coletivo, nunca individual.

Assim, os direitos humanos passam a ser pensados a partir de fundamentos contingentes, no sentido trazido por Butler (1998), que para cumprirem seu papel de expansão das formas vivíveis de vida, devem permanecer sempre abertos à contestação e à ampliação de suas fronteiras, incluindo novas experiências humanas. Isso requer, ainda, um deslocamento da relação entre a ideia de 'direitos humanos' e a ideia de 'indivíduo' moderno. Esse 'indivíduo', dotado de 'direitos em decorrência de sua natureza', deve sair de cena para fazer surgir uma compreensão mais relacional do humano e, bem assim, também dos direitos.

Como ser relacional, compreende-se o humano não mais como definido a partir de sua autonomia individual, mas das relações que trava com os demais e que o constituem enquanto sujeito (Butler, 2018). Não se trata de uma simples forma de comunitarismo, mas de compreender que na esteira da história toda ética é coletiva, inclusive aquela dos direitos. Esse coletivo, no entanto, não deve jamais ser olhado de forma holística, o que nos traria o risco de impor as percepções das maiorias como percepções estáticas da comunidade, em termos abordados em trabalhos anteriores (Santos, 2019). Esse coletivo deve, na verdade, ser visto como dinâmico, complexo e conflitual, de forma que a verdadeira ética seja sempre aquela capaz de possibilitar a necessária convivência entre os diferentes sujeitos em conflito; aquela, enfim, que substitua a gramática do inimigo nos conflitos sociais, pela gramática do adversário (Mouffe, 1996).

Enfim, tal reflexão pareceria indicar que o fundamento dos direitos humanos não deveria ser buscado naquilo que possuiríamos em comum como indivíduos isolados (como uma natureza biológica similar), mas naquilo que possuímos em comum apenas no sentido da nossa interconexão como sujeitos sociais, sempre profundamente ligados à existência de diversos Outros, que nos constituem enquanto Eu humano (Butler, 2018).

Se ser 'humano' não é nunca uma experiência individual, mas sempre uma experiência coletiva, é preciso então evidenciar o quanto ser ou não dotado de direitos é também sempre uma experiência coletiva e nunca uma experiência individual. As exclusões ocorrem por experiências compartilhadas com grupos de pessoas, marcadas por atributos semelhantemente excluídos das concepções hegemônicas do 'humano pleno', expondo-as como grupos à violência e à exclusão.

Nessa esteira, no lugar da 'dignidade humana' como fundamento desses direitos, e todas as suas problemáticas de definição, vislumbra-se a potencialidade do uso do conceito butleriano de 'precariedade' (Butler, 2015). Isso porque se trata de conceito profundamente relacional e social, além de identificar talvez a única característica imanente que conecta a todos nós: a exposição à morte, ainda que em diferentes graus em decorrência das estruturas sociais. De fato, ao menos no nível tecnológico do presente, todo e qualquer ser humano está exposto à fatalidade da morte; essa exposição, por seu turno, será minimizada ou maximizada exatamente a depender de quem seja esse humano e a que grupos este pertença.

Viver é, então, estar exposto à morte. Os enquadramentos que nos constituem como humanos realizam o corte de como essa exposição imanente se distribuirá. A precariedade, como conceito, surge da morte compreendida como fatalidade em comum. É entendida, portanto, como a consequência do fato de que viver significa viver socialmente; e isso porque a vida requer que várias condições sociais e econômicas sejam atendidas para que seja mantida enquanto uma vida (Butler, 2015, p. 31). A precariedade nos marca a todos porquanto vivos, ou seja, expostos à morte.

Mas a precariedade não permanece pensada apenas a partir do elemento corpo-morte. A precariedade é, também, 
profundamente social, se distribuindo de maneira desigual a depender dos enquadramentos que estejam em operação. Estamos diante do fato de que determinadas pessoas - ou grupos de pessoas - são expostas a condições econômicas e sociais menos favoráveis, ou seja, expostas à morte de forma muito mais intensa do que outras. Assim, a precariedade é um contexto social, intensamente imerso num mundo e em uma história de distribuição desigual de recursos. Se "a vida exige apoio e condições possibilitadoras para poder ser uma vida vivível” (Butler, 2015, p. 40) esses apoios e condições estão condicionados às regras e aos enquadramentos que orientam os esquemas de reconhecimento daquilo que faz emergir um corpo como uma vida efetivamente humana, que importa e que é passível de luto em caso de perda.

Ou seja, a precariedade parece ser em um só tempo um atributo generalizável no contexto da vida humana - e mesmo da vida em geral -, mas cujos contornos apenas se tornam possíveis mediante os contextos socioculturais específicos em que determinada vida humana está inserida. Se em algum limite parece adequado dizer que todos somos precários, deveríamos escolher dizer - em sintonia com a distribuição desigual dos recursos que possibilitam a minimização dessa precariedade - que alguns de nós são precarizados. Precarizados no sentido de que a precariedade não pode ser compreendida como uma condição vivida igualmente por todos os corpos, mas que se faz sentir de formas desiguais, mediada pelas normas de reconhecimento daquilo que é, ou não é, humano.

O uso de precarizados ao invés de precários, nesse sentido - ou de vulnerabilizados ao invés de vulneráveis - parece ser importante nos marcos de uma teoria que enfoca as normas culturais que criam sujeitos normais e abjetos, em uma negativa de um enfoque naturalizante sobre essa normalidade ou abjeção. Além disso, a opção aponta ainda para a necessidade de pontuar que reconhecer a precariedade compartilhada na experiência do humano não pode ser - e não é - deixar de abordar as formas desiguais através das quais essa precariedade se distribui e se impõe, nos termos de regras sociais de reconhecimento.

Nesse sentido, a precariedade - e os processos de maximização da precariedade, ou de precarização - parecem trazer um importante benefício: a possibilidade de pensar o sofrimento humano de forma amplamente compartilhada - a partir do fato de que viver, em quaisquer condições culturais, é estar mais ou menos exposto à morte -, mas sem ignorar as manifestações particulares desse sofrimento no contexto das regras de reconhecimento sócio-históricas vividas pelos corpos em particular, sem universalizar esse sofrimento a partir de princípios e vieses ahistóricos, portanto. Sem ignorar, principalmente, que os processos de luta só se organizam e se significam nos termos dessas regras em específicas, sendo impossível traduzi-los em termos dos significados pretensamente universais de que se vestem os direitos humanos.

O elemento da corporalidade aqui é central. Pensar direitos torna-se pensar o fato de que uma vida, porque corpórea e, portanto, matável, requer garantias sociais para que se mantenha como uma vida. Essas garantias, ou a ausência delas, dependem de condições sociais e culturais específicas (Butler, 2018) as quais não podem ser ignoradas quando nos questionamos sobre os processos de criação e aplicabilidade dos direitos humanos.

Em especial, o uso do conceito de precariedade, bem como o abandono do conceito de dignidade, parece possibilitar uma construção teórica e política outra no campo dos direitos humanos, os quais têm se apresentado ainda como importante instrumental para movimentos sociais os mais variados.

Vê-se, ainda, que a precariedade pode ocupar o papel de fundamento contingente (Butler, 1998). É fundamento, visto que a distribuição desigual que maximiza a exposição à morte de uns enquanto minimiza a de outros, oferece um ponto de partida para a necessidade de mudança que inspira a luta por direitos. É fundamento, ainda, pois que essa realidade de maximização de minha vida a partir de condições sociais que ao mesmo passo minimizam a vida do Outro redunda em uma circunstância ética que deve ser questionada; a minha constituição como humano na medida em que o Outro é julgado como menos humano e exposto à morte, é enfim, violência ética (Butler, 2017) e como tal deve ser combatida. Nesse ponto, a precariedade como fundamento convive com uma disposição ética decorrente da inexorável convivência dos seres humanos uns com os outros, que se realiza na disposição do direito a ter direitos (Butler, 2018), que deve se traduzir no acesso às condições sociais de minimização 
da exposição de cada um à morte.

Além de fundamento, a precariedade é ainda contingente. Afinal, a maneira como certas vidas são mais ou menos expostas à morte, quais sejam essas vidas, ou mesmo o porquê de serem esses processos colocados em operação, vai depender de cada contexto e realidade histórica.

Assim, essa compreensão oferece um olhar ressignificado acerca dos fundamentos dos direitos humanos, especialmente a partir das problemáticas que neles se identificam quando vemos em curso lutas por direitos humanos de grupos tais como a população LGBTI+.

\section{Conclusão}

Enquanto os direitos humanos permanecem como estratégia de luta de movimentos sociais diversos ao redor do globo, parece necessário que permaneçamos pensando acerca deles e colocando-os para funcionar. Em nossa teoria e prática de direitos humanos, no entanto, esconde-se um sujeito humanista padronizado, que produz exclusões e afirma uma determinada norma de reconhecimento, a diferenciar os corpos em níveis de humanidade.

Ressignificar o uso e a prática dos direitos humanos passa pela necessária reflexão acerca do que os fundamenta. Parece ser necessário nesse sentido pensar um fundamento que se afaste ao máximo possível do humanismo kantiano. Para isso, tratase de ver os direitos humanos não como valores éticos considerados pré-discursivos e universalmente válidos; nem tampouco apenas como normas positivadas nesse ou naquele sistema internacional ou nacional. Mas sim, de ver os direitos humanos como os diferentes processos de luta em que corpos se engajam quando expostos à precarização pelas condições sociais que organizam a distribuição do reconhecimento e dos recursos e que intensifica sua exposição à morte. Processos de luta não mais pela dignidade, portanto, mas a partir da (e em combate à) precarização.

Essa postura teórica pode ofertar uma teoria e prática dos direitos humanos que não se exerça a partir de dívidas com as concepções humanistas acerca dos direitos e de quem os detêm. Pode abrir espaço para focalizar os processos de luta e os agentes que se constituem nessas lutas, sem pressupor finalidades e sujeitos por trás dessas finalidades. Pode, portanto, sepultar a metafísica do humano sem esvaziar a potência política dos direitos, quando pensados de forma dinâmica e em processo.

Lutar por direitos é, então, lutar contra a precariedade; é denunciar as desigualdades dessas estruturas sociais que maximizam a precariedade de alguns. É denunciar, enfim, o próprio conceito de natureza humana e de direitos humanos na perspectiva hoje difundida, como parte dessas estruturas que possibilitam a distribuição desigual dos níveis de precariedade entre as criaturas humanas.

Reivindicar direitos humanos pode ser pensado então, como denunciar as concepções culturais excludentes e a partir disso reivindicar a efetivação de condições sociais concretas, passíveis de minorar os níveis de precariedade de diferentes grupos sociais a partir dessas concepções culturais. Assim, percebe-se também a possibilidade de superar o abismo que muitas vezes se visualiza entre possuir direitos nos sentidos formal e material.

Em uma teoria de direitos humanos vistos como estruturas de proteção contra a precariedade, os direitos serão sempre contextualmente imaginados e criados e apenas se realizarão como existentes a partir de sua manifestação de forma concreta e material.

\section{Referências}

Adorno, T. W. (2003). Notas de Literatura I. Ed. 34

Andrade, R. C. (2000) Kant: a liberdade, o indivíduo e a república. In: Weffort, F. (org.). Os clássicos da política, 2. Ática. 47-100

Bernstein, M., \& Reimann, R. (2001) Queer Families and the Politics of Visibility. In: Bernstein, M., \& Reimann, R. (ed.). Queer families, queer politics. Columbia University Press, p. 01-18 
Research, Society and Development, v. 10, n. 16, e180101623105, 2021

(CC BY 4.0) | ISSN 2525-3409 | DOI: http://dx.doi.org/10.33448/rsd-v10i16.23105

Butler, J. (1998) Fundamentos contingentes: o feminismo e a questão do 'pós-modernismo'. Cadernos pagu, 11, 11-42

Butler, J. (2003). O parentesco é sempre tido como heterossexual? Cadernos Pagu, 21, 219-260

Butler, J. (2007). El gênero en disputa: El feminismo y la subversión de la identidad. Trad. Antonia Muñoz. Espasa Libros

Butler, J. (2015). Quadros de Guerra: quando a vida é passivel de luto? Civilização Brasileira

Butler, J. (2017). Relatar a si mesmo: crítica da violência ética. Autêntica Editora

Butler, J. (2018). Corpos em aliança e a política das ruas: notas para uma teoria performativa de assembleia. Rio de Janeiro: Civilização Brasileira.

Costa, P. (2012). Poucos, muitos, todos: lições de história da democracia. Editora UFPR

Felski, R. (1995). The Gender of Modernity. Harvard College.

Flores, J. H. (2009) A (re)invenção dos Direitos Humanos. Fundação Boiteux

Formento, J. dos A. S, \& Almeida, S. dos S. de. (2020). Violência homofóbica: Revisão sistemática da literatura. Research, Society and Development, 9(7), e848974939

Foucault, M. (2008). Segurança, Território e População: curso dado no Collège de France (1977-1978). Martins Fontes

Foucault, M. (2010) Em defesa da sociedade: curso no Collège de France (1975-1976). Editora WMF Martins Fontes

Foucault, M. (2014). História da Sexualidade: a vontade de saber. Paz e Terra

Haider-Markel, D. P. (2001) Defense, Morality, Civil Rights, and Family: The Evolution of Lesbian and Gay Issues in the U.S. Congress. In: Bernstein, M. \& R., R. (ed.). Queer families, queer politics. Columbia University Press, p. 358-378

Hunt, L. (2012). A invenção dos direitos humanos: uma história. A Página

Jackson, S. (1998) Sexual politics: feminist politics, gay politics and the problem of heterosexuality. In: Carver, T., \& Mottier, V. (editors). Politics of Sexuality: identity, gender, citizenship. Routledge: 68-78

Kingdom, E. (1991). What's wrong with rights? Problems for Feminist Politics of Law. Edinburgh: Edinburgh University Press.

Maldonado-Torres, N. (2019). Da colonialidade dos Direitos Humanos. In: Santos, B. S., \& Martins, B. S. (orgs). O pluriverso dos direitos humanos: a diversidade das lutas pela dignidade. Lisboa: Edições 70, 93-119

Miskolci, R. (2007). Pânicos morais e controle social - reflexões sobre o casamento gay. Cadernos Pagu, 28, 101-128.

Miskolci, R., \& Campana, M. (2017) "Ideologia de gênero": notas para a genealogia de um pânico moral contemporâneo. Revista Sociedade e Estado, 32 (3), $725-747$

Morrison, W. (2006). Filosofia do Direito: dos gregos ao pós-modernismo. Martins Fontes

Mouffe, C. (1996). O regresso do político: trajectos. Gradiva Publicações

Paiva, A. C. S. (2007). Reserva e Invisibilidade: a construção da homoconjugalidade numa perspectiva micropolítica. In: Grossi, M., Uziel, A. P., Mello, L. Conjugalidades, Parentalidades e Identidades Lésbicas, Gays e Travestis. Garamond.

Ribeiro, L. P., Zanin, H. da S., Silva, I. P. da, \& Dias, A. F. M. (2020). Políticas organizacionais de inclusão: Práticas de respeito às minorias sexuais e de gênero. Research, Society and Development, 9(1), e176911894

Ruzyk, C. E. P. (2019). A Metodologia do Direito Civil no pensamento de Luiz Edson Fachin. In: Ehrhardt Junior, M., \& Cortiano Junior, E. (coord.). Transformações no Direito Privado nos 30 anos da Constituição: estudos em homenagem a Luiz Edson Fachin. Fórum, 27-35

Santos, A. R. B. d. (2019) Feminismos em tradução: por uma perspectiva dialógica dos direitos humanos das mulheres. In: Bertotti, B. M., Viana, A. C. A., Kreuz, L. R. C., Caleffi, R. (orgs.) Gênero \& Resistência: memórias do II Encontro de Pesquisa por/de/sobre Mulheres, 1, 165-186

Santos, B. S., \& Martins, B. S. (2019). Introdução. In: Santos, B. S., \& Martins, B. S. (orgs). O pluriverso dos direitos humanos: a diversidade das lutas pela dignidade. Edições 70, 11-37 